\title{
Evaluation of the effect of probiotic as add-on therapy with conventional therapy and alone in malaria induced mice
}

\author{
Eshani Mahajan ${ }^{1}$, Shweta Sinha², Alka Bhatia ${ }^{3}$, Rakesh Sehgal ${ }^{2}$ and Bikash Medhi ${ }^{{ }^{*}}$ (1)
}

\begin{abstract}
Objective: Chloroquine is used as a conventional drug therapy for the treatment of malaria. The existence of resistance to chloroquine shown among various species of Plasmodium leads to the search for more efficacious therapy to treat malaria. Probiotic (Lactobacillus casei) has been tried as an add-on therapy with chloroquine. Probiotics are ingested microorganisms associated with a beneficial effect on humans and other species. The study was done to check the efficacy of $L$. casei as an add-on therapy along with conventional drug therapy (chloroquine) to treat malaria.

Results: Probiotic in combination with chloroquine showed complete suppression in parasitemia rate. Representation of parasitemia rate was done using mean \pm SD. $p<0.05$ is considered as statistically significant. The results showed a reduction in parasitemia with probiotic treatment, which was further confirmed through histological observation of two major organs, the liver and spleen. Interestingly, further suppression of parasitemia and hemosiderosis was observed when probiotic was given along with chloroquine.
\end{abstract}

Keywords: Chloroquine, Probiotic, Malaria, Lactobacillus casei

\section{Introduction}

Malaria is among one of the deadliest threats for the human species which is caused by various strains of malaria parasites e.g., Plasmodium falciparum, Plasmodium vivax, Plasmodium ovale, Plasmodium malariae, and Plasmodium knowlesi. The risk of developing malaria is about 3.3 billion all over the world [1]. The immune response plays a major role in the pathophysiology of malaria. Various different immune proteins, which are released during the parasite attack can prohibit the growth of the same. Moreover, some signaling pathways act against the parasite e.g., Tolls like receptor,

\footnotetext{
*Correspondence: drbikashus@yahoo.com

1 Department of Pharmacology, Postgraduate Institute of Medical

Education \& Research, Research Block B, 4th Floor, Room no 4043,

Chandigarh 160012, India

Full list of author information is available at the end of the article
}

signal transducers and activator of transcription pathway (STAT), and Janus kinase pathway (JNK) [2]. Chloroquine was the choice of drug for the treatment of $P$. falciparum malaria, but these days there is an emergence of resistance among $P$. falciparum species [3]. Microorganisms that are believed to provide health benefits to the consumer are known as probiotics. These are generally gram-positive bacteria which are mainly isolated from gut microflora and are known to provide an enhancement in the immune response to the consumer. Probiotics provide strain-specific effectiveness as it has immune stimulatory properties against various pathogens and has ability to modulate intestinal microorganisms. Probiotics have shown their effects on various epithelial cells, Payer's patches cells, and immune cells [4]. The result of this interaction is an increase in the number of antibodies such as, IgA and IgM [5]. Past studies had shown that gut microbiota correlates with the severity of malaria parasite

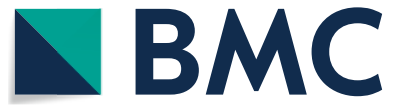

(C) The Author(s) 2021. This article is licensed under a Creative Commons Attribution 4.0 International License, which permits use, sharing, adaptation, distribution and reproduction in any medium or format, as long as you give appropriate credit to the original author(s) and the source, provide a link to the Creative Commons licence, and indicate if changes were made. The images or other third party material in this article are included in the article's Creative Commons licence, unless indicated otherwise in a credit line to the material. If material is not included in the article's Creative Commons licence and your intended use is not permitted by statutory regulation or exceeds the permitted use, you will need to obtain permission directly from the copyright holder. To view a copy of this licence, visit http://creativecommons.org/licenses/by/4.0/. The Creative Commons Public Domain Dedication waiver (http://creativecommons.org/publicdomain/zero/1.0/) applies to the data made available in this article, unless otherwise stated in a credit line to the data. 
infection. Moreover, probiotics have beneficial effects against malaria parasite infection [6]. Several studies which have specific protocol towards understanding the molecular mechanism of probiotics needed to be done which involves its clinical application as well. The present study evaluates the effects of probiotic (Lactobacillus casei) on parasitemia count, histopathological changes in malaria-infected mice and tried to demonstrate the synergistic effect of this probiotic, along with chloroquine (conventional drug therapy) which can further lead to the development of fixed-dose probiotic combinations for the treatment of malaria.

\section{Main text}

\section{Materials and methods}

\section{Study area}

The study was designed as a single experimental, observational study which was conducted in the Department of Parasitology and Department of Pharmacology at the PGIMER, Chandigarh, India, for a duration of 1 year after taking approval from the Institutional Animal Ethics Committee (IAEC), PGIMER, Chandigarh, vide Ref No. 81/IAEC/521. Balb/c mice $(n=32)$ were obtained from Institutional Central Small Animal Facility, PGIMER, Chandigarh, and were allocated to the following equally sized $(\mathrm{n}=8)$ groups as: (i) Group I (non-infected) (ii) Group II (Infected group) (iii) Group III (P. berghei $+L$. casei) (iv) Group IV (P. berghei $+L$. casei + chloroquine). Laboratory standard cages were used for housing of the mice and acclimatized for 7 days prior to the start of experiments. Standard livestock feed and clean drinking water were given to them. This study was conducted according to the Committee for the Purpose of Control and Supervision of Experiments on Animals (CPCSEA) guidelines.

\section{Treatment procedure}

PBS was administered to the mice of Group I (noninfected) for four consecutive days, while P. berghei strain NK-65 infection was given to all other groups except Group I. The mice were infected via injecting $0.2 \mathrm{~mL}$ suspension of 10 parasitized erythrocyte intraperitoneally as described previously [7]. Samples of blood were taken from the tail of mice. Parasitemia $\mathrm{ra}^{6}$ te were determined after preparation of thin blood smear following Giemsa staining. $P$. berghei infection was given to the second group. $L$. casei along with $P$. berghei was given to the third group. Chloroquine was administered to the mice at the dose of $15 \mathrm{mg} / \mathrm{kg}$ once a day for four consecutive days in the fourth group [7]. After completion of all the experimental procedures, animals were sacrificed by giving anaesthesia followed by cervical dislocation. This euthanasia procedure was done according to CPCSEA guidelines.

\section{Determination of parasitemia}

For the determination of the baseline parasitemia, thin smear was made using the blood sample [8]. By using a light microscope at $1000 \times$ magnification, we have checked the parasitemia rate by counting infected erythrocytes (parasitized) out of the 200 erythrocytes (both infected and non-infected) per field and counting continues till 10 fields. The following formula used for the calculation of parasitemia rate/percentage:

$$
\begin{aligned}
& \text { PR(Parasitemia Rate }) \\
& =\frac{\text { Total number of } p R B C(\text { parasitized } R B C)}{\text { Total number of } R B C(\text { infected and non }- \text { infected })} \\
& \quad \times 100
\end{aligned}
$$

\section{Histopathology}

For histopathological studies, the animals were sacrificed by cervical dislocation on the fourth day of respective treatment and the organs were harvested. Pathological changes were observed in two organs, i.e., the liver and spleen. Tissue from each group was fixed in 10\% formalin and embedded with paraffin. After routine processing, paraffin sections from each tissue were cut into $5 \mu \mathrm{m}$ thickness and stained with hematoxylin and eosin. The photomicrographs of the relevant stained sections were taken with the aid of a light microscope [9]. The following scores were used to grade the degree of histopathological changes or lesions observed in the organs: not observed $(-)$, mild $(+)$, moderate $(++)$, and severe $(+++)$.

\section{Data analysis}

Data analysis was done using statistical software, i.e., SPPS Version 21. Parasitemia count is represented as mean \pm SD. Post hoc analysis was done by using ANOVA and Bonferroni multiple comparison tests for the comparison of means. $\mathrm{p}<0.05$ is considered statistically significant.

\section{Results}

Parasitized RBCs were seen using light microscopy on the fourth day of inoculation by using the Giemsa staining technique on the microscopic slides. On the first day as compared to Group II (P. berghei treated), Group IV (P. berghei $+L$. casei + chloroquine) has shown a statistically significant decrease $(\mathrm{p}<0.01)$ in parasitemia \%, On second day Group III (P.berghei + L. casei) and Group IV (P. berghe $i+L$. case + chloroquine) has also shown a statistically significant decrease in parasitemia \% $(\mathrm{p}<0.05$ and $\mathrm{p}<0.001)$ as compared to group II $(P$. berghei) while 


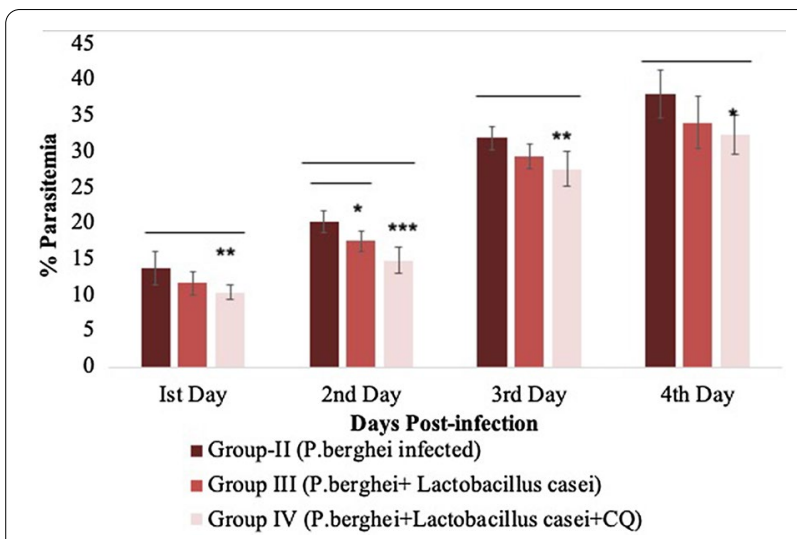

Fig. 1 Graph showing percentage Parasitemia. The data are represented as mean $\pm S D$. Statistical significance of data are given as ${ }^{*} p<0.05 ;{ }^{* *} p<0.01 ; * * * p<0.001$

on day third, Group IV has shown statistical significant $(\mathrm{p}<0.01)$ decrease in parasitemia \% as compare to group II. Finally, on the last fourth day group IV has shown a statistically significant decrease in parasitemia $\%(\mathrm{p}<0.05)$ as compared to the $P$. berghei treated group, shown in Fig. 1. Overall, it has been shown that there is a reduction in parasitemia \% when $L$. casei alone and $L$. casei along with chloroquine was given as compared to the infected group ( $P$. berghei treated), shown in (Additional file 1: Figure S1).

There were no changes found in the case of a control group as it has shown normal pathology (Figs. 2a and $3 a)$. Hemosiderosis and periportal inflammation in the liver section was found more in an infected group (2b) but there is a reduction of hemosiderosis and periportal inflammation when treatment of $L$. casei (2c) was given and further suppression was seen in the group treated with chloroquine and $L$. casei $(2 \mathrm{~d})$. In the case of the spleen, megakaryocytic hyperplasia, lymphoid hypoplasia along with hemosiderosis have been seen in the infected group (3b). It has become mild and traces of hemozoin pigments were seen when $L$. casei treatment was given (3c) but these were further reduced in the chloroquine and $L$. casei treated group (3d).

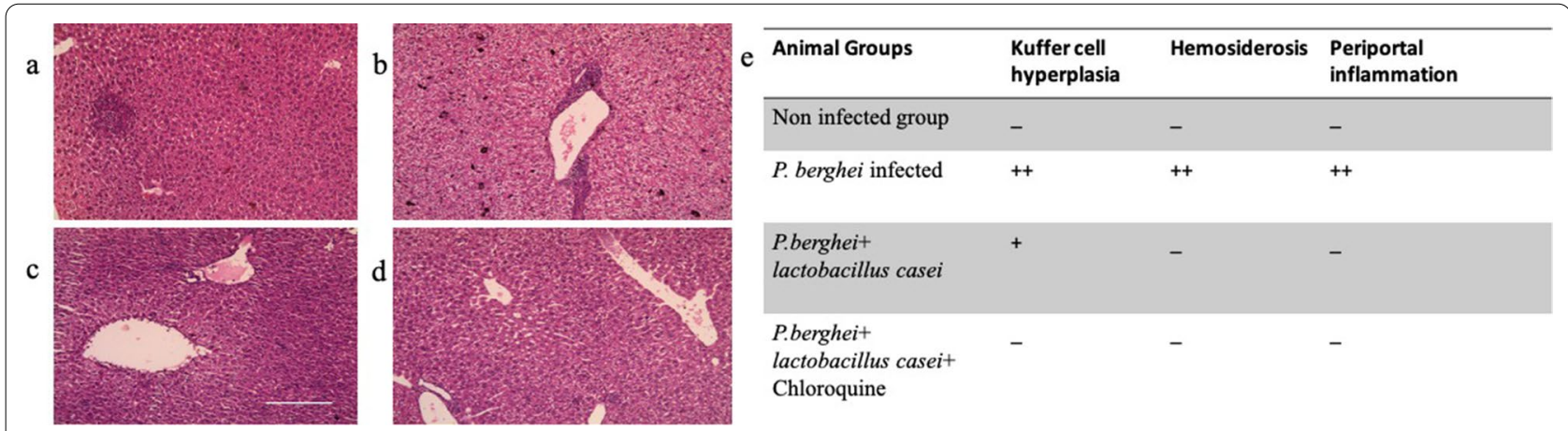

Fig. 2 LS of control liver and treated liver under high magnification (200x). a Group I (Non-infected group): In this liver showing no periportal inflammation, hemosiderosis and Kuffer cell hyperplasia (b) Group II (P. berghei infected): Showing severe periportal inflammation with Kuffer cell hyperplasia and hemosiderosis (c) Group III (P.berghei + L. casei) liver: showing mild kuffer cell hyperplasia, periportal inflammation and traces of hemosiderosis (d) Group IV (P. berghei + L. casei + Chloroquine) liver: showing Kuffer cell hyperplasia, hemosiderosis and traces of periportal inflammation. e The scoring chart to show the effect of treatment on histopathological changes in the liver section
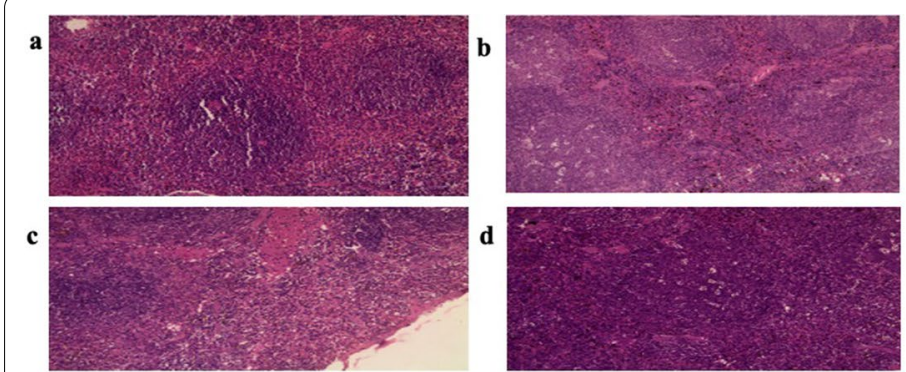

\begin{tabular}{|c|c|c|c|}
\hline Animal Groups & $\begin{array}{l}\text { Megakaryocytic } \\
\text { hyperplasia }\end{array}$ & Hemosiderosis & $\begin{array}{l}\text { Lymphoid } \\
\text { hypoplaisa }\end{array}$ \\
\hline Non-infected & - & - & - \\
\hline P. berghei infected & +++ & ++ & + \\
\hline $\begin{array}{l}\text { P.berghei+ } \\
\text { lactobacillus casei }\end{array}$ & +++ & - & - \\
\hline $\begin{array}{l}\text { P.berghei+ lactobacillus } \\
\text { casei+ Chloroquine }\end{array}$ & - & + & - \\
\hline
\end{tabular}

Fig. 3 LS of Spleen under high magnification (200x). a Group I (Non-infected group) spleen (b) Group II (P. berghei infected) spleen: showing severe hemosiderosis, lymphoid hypoplasia and Megakaryocytic hyperplasia (c) Group III (P. berghei + L. casei) spleen: showing mild hemosiderosis and Megakaryocytic hyperplasia (d) Group IV (P. berghei + L. casei + Chloroquine) spleen: showing mild hemosiderosis, Megakaryocytic hyperplasia, and no lymphoid hypoplasia. e The scoring chart to show the effect of treatment on histopathological changes in the spleen section 


\section{Discussion}

This study was planned to show the synergistic effect of L. casei (Probiotic) along with chloroquine in malariainduced mice. $L$. case $i$ were given at $0.1 \mathrm{~mL}$ for 3 days. A similar study was conducted by Oyetayo et al. [10], in which they showed Lactobacillus acidophilus and L. casei protective effects. The rat has been dosed with Lactobacillus and showed lowering of serum alanine aminotransferase activities which have values of 15.50 and 18.27 IU/L as compared to that of the control. Liver functions were improved by $L$. casei which was later confirmed by toxicological data of rat serum. In the present study, probiotic treatment along with conventional drug therapy showed statistically significant reduction in the parasitemia rate. There was an improvement in histopathological damages that are caused by the plasmodium parasite in organs like the liver and spleen. Hence, the present study confirmed that the use of probiotics as add-on therapy along with conventional drug therapy has beneficial effects. Chloroquine when given along with $L$. casei causes further decrease in the parasitemia count leading to maximum suppression of the parasite growth. Blood film microscopic examination was found to be lesser than $2 \%$ within the period of four days before starting treatment, while chloroquine $+L$. case $i$ cleared parasitemia on the third day of treatment. A previous study done by Khalifa EA, 2016, has shown that as compared to the non-treated group the $L$. casei treated group has decreased the parasite load in the infected mice. So, probiotics can be considered as a promising and hopeful alternative for the treatment of various parasitic diseases. Different standard drug therapies in combination with probiotics can provide a definite treatment to eradicate the various parasitic infections [11]. Moreover, probiotics treatment has also been effective in treating bacterial infections as well, e.g., Salmonella. Probiotics have several mechanisms of action for example, it increases the production of acid which kills the acid-sensitive bacteria or it releases the bacteriocins that may inhibit the growth of other pathogenic bacteria [12]. Another study which has been conducted in mice infected with Strongyloides venezuelensis, shown a reduction in the number of worms (about 33\%) and egg output upon giving probiotics and has also improved the immune responses. However, the factors responsible for these effects are still not clear [13]. On the other hand, the study which was done by Juliette Guitard et al., has shown that administration of L.casei mixture (daily) was unable to eradicate the complete parasite load (Cryptosporidium parvum) in the neonatal rat model. The reason for this may be due to the lack of production of INF- $\gamma$ which could show the protective effect against the parasite [14].
This study has shown that when $L$. casei is given along with the standard drug therapy (chloroquine) it shows a synergistic effect in the mice model of malaria as it has reduced the parasitemia count and improved the pathological changes that appeared after getting the infection.

\section{Limitations}

The study includes the only preliminary finding that shows the only effect of $L$. case $i$ as one of the probiotics, on malaria parasite in vivo environment. However, it lacks to depict host response while taking probiotics in case of malaria infection. A more elaborated protocol is required for further deeper investigations such as studying of the involvement of innate and adaptive immunity through estimation of antibodies, T-subset regulation, and cytokines estimation. Additionally, experiments such as a survival plot would better explain the usefulness of these prophylactic measures.

\section{Abbreviations}

ANOVA: Analysis of variance; ATCC: American type culture collection; IgA: Immunoglobulin A; IL-10: Interleukin-10; INF-Y: Interferon-gamma; IU/L: International units per liter; L.casei: Lactobacillus casei; PBS: Phosphate Buffer Saline; RBCs: Red blood corpuscles; SD: Standard deviation; SPSS: Statistical Package for the Social Sciences.

\section{Supplementary Information}

The online version contains supplementary material available at https://doi. org/10.1186/s13104-021-05661-1.

Additional file 1: Figure S1. Giemsa Stain slide of parasitemia on fourth day of treatment observed under $1000 \times$ magnification.

\section{Acknowledgements}

Not Applicable.

\section{Authors' contributions}

$\mathrm{BM}, \mathrm{RS}$ designed the study and contributed reagents and materials. EM performed experiments and AB, EM and SS did the result's analysis. EM, SS and $\mathrm{BM}$ helped in the writing, reviewing, and editing of the manuscript. All authors read and approved the final manuscript.

\section{Funding}

No funding support has been provided in the design of the studies, data collection, analysis, interpretation of data, and in writing of the manuscript from any funding agencies (public, commercial, or not-for-profit sectors).

\section{Availability of data and materials}

All data generated or analyzed during this study are included in this published article and its supplementary information files.

\section{Declarations}

Ethics approval and consent to participate

The ethical approval was taken from Institute Animal Ethics Committee, Project Ref No. 81/IAEC/521, at Postgraduate Institute of Medical Education and Research, Chandigarh, India for maintenance of $P$. berghei NK-65 strains in Balb/c strain of mice. 


\section{Consent for publication}

Not applicable.

\section{Competing interests}

The author declares that they have no competing interests.

\section{Author details}

'Department of Pharmacology, Postgraduate Institute of Medical Education \& Research, Research Block B, 4th Floor, Room no 4043, Chandigarh 160012, India. ${ }^{2}$ Department of Medical Parasitology, Postgraduate Institute of Medica Education and Research, Chandigarh 160012, India. ${ }^{3}$ Department of Experimental Medicine and Biotechnology, Postgraduate Institute of Medical Education and Research, Chandigarh 160012, India.

Received: 3 February 2021 Accepted: 17 June 2021

Published online: 30 June 2021

\section{References}

1. Sinha S, Medhi B, Sehgal R. Challenges of drug-resistant malaria. Parasite. 2014;21:61.

2. Belachew EB. Immune response and evasion mechanisms of Plasmodium falciparum parasites. J Immunol Res. 2018:2018:6529681.

3. Martin RE, Marchetti RV, Cowan Al, Howitt SM, Broer S, Kirk K. Chloroquine transport via the malaria parasite's chloroquine resistance transporter. Sci. 2009;325:1680-2

4. Szajewska H, Kotowska M, Mrukowicz JZ, Armańska M, Mikołajczyk W. Efficacy of Lactobacillus $G G$ in prevention of nosocomial diarrhea in infants. J Pediatr. 2001;138:361-5.

5. Perdigon G, Alvarez S, Rachid M, Agüero G, Gobbato N. Immune system stimulation by probiotics. J Dairy Sci. 1995;78:1597-606.
6. Dong Y, Manfredini F, Dimopoulos G. Implication of the mosquito midgut microbiota in the defense against malaria parasites. Plus Pathog 2009:5:e1000423.

7. Abolghasemi E, Moosa Kazemi SH, Davoudi M, Reisi A, Satvat MT. Comparative study of chloroquine and quinine on malaria rodents and their effects on the mouse testis. Asian Pac J Trop Biomed. 2012;2(4):311-4.

8. Tepongning RN, Mbah JN, Avoulou FL, Jerme MM, Ndanga EK, Fekam FB. Hydroethanolic extracts of erigeron floribundus and azadirachta indica reduced Plasmodium berghei parasitemia in Balb/c Mice. Evid Based Complement Alternat Med. 2018;2018:5156710.

9. Carleton's histological technique. Ulster Med J. 1967 Summer;36(2):172.

10. Oyetayo VO, Adetuyi FC, Akinyosoye FA. Safety and protective effect of Lactobacillus acidophilus and Lactobacillus casei used as probiotic agent in vivo. Afr J Biotech. 2003:2(11):448-52.

11. Khalifa EA. Probiotics as a promising treatment of experimental cryptosporidiosis in an immunosuppressed mouse model. Int J Curr Microbiol. 2016;5(3):97-106

12. Andino A, Zhang N, Sanchez SD, Yard C, Pendleton S, Hanning I. Characterization and specificity of probiotics to prevent salmonella infection in mice. Functional Foods Health Dis. 2014:4:370-80.

13. Oliveira-Sequeira TC, David ÉB, Ribeiro C, Guimarães S, Masseno AP, Katagiri S, Sequeira JL. Effect of Bifidobacterium animalis on mice infected with Strongyloides venezuelensis. Rev Inst Med Trop Sao Paulo. 2014;56(2):105-9.

14. Guitard J, Menotti J, Desveaux A, Alimardani P, Porcher R, Derouin F, Kapel $\mathrm{N}$. Experimental study of the effects of probiotics on Cryptosporidium parvum infection in neonatal rats. Parasitol Res. 2006;99(5):522-7.

\section{Publisher's Note}

Springer Nature remains neutral with regard to jurisdictional claims in published maps and institutional affiliations.
Ready to submit your research? Choose BMC and benefit from:

- fast, convenient online submission

- thorough peer review by experienced researchers in your field

- rapid publication on acceptance

- support for research data, including large and complex data types

- gold Open Access which fosters wider collaboration and increased citations

- maximum visibility for your research: over $100 \mathrm{M}$ website views per year

At $\mathrm{BMC}$, research is always in progress.

Learn more biomedcentral.com/submissions 